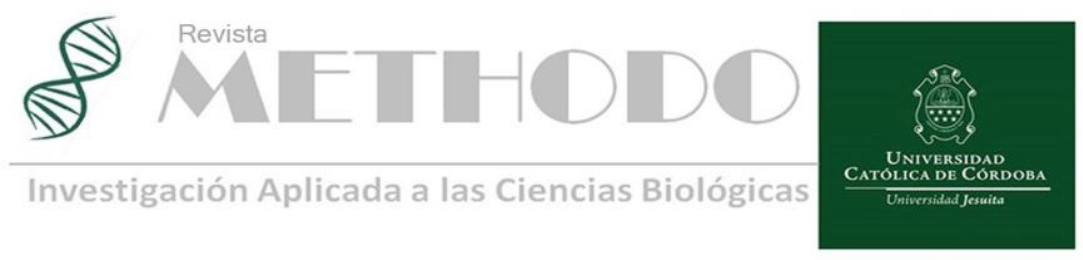

NOTA DE LOS EDITORES Rev. Methodo 2020;5(4):125-126 https://doi.org/10.22529/me.2020.5(4)01

Redactado 27 Agos. 2020 | Publicado 05 Oct. 2020

\title{
La importancia de la indización de una revista científica
}

\section{The importance of indexing a scientific journal}

Las ciencias, por estos tiempos, han alcanzado un desarrollo logarítmico, con avances científicos que han cambiado el modo de vida de los pueblos en distintas latitudes de nuestro planeta. Las investigaciones, en nuestro caso en el campo de las ciencias biológicas, están al alcance de nuestras manos como nunca ha ocurrido.

Para ello, estamos simplemente a un clic, para ingresar a distintas bases de datos donde podemos acceder a numerosas revistas, muchas de ellas en forma libre $y$ gratuita, que han permitido democratizar el acceso, sin que ello signifique un menoscabo en su calidad.

Las bases de datos son herramientas que permiten almacenar y administrar la información para lograr un uso más fácil y eficiente de las mismas. En la actualidad, y gracias al desarrollo tecnológico de campos como la informática e internet, la mayoría de las plataformas de contenido científico tienen formato electrónico, que permite de una manera sencilla almacenar datos que pueden alcanzar los investigadores y lectores de ciencia.

Ahora bien, para que una revista científica pueda ser localizada en esas bases de datos, debe estar indizada o indexada (ambos términos pueden utilizarse indistintamente). Pero para que ello ocurra se toman en cuenta ciertos criterios indispensables como la calidad del contenido de las investigaciones, sus características técnicas o formales y el impacto que tiene en la comunidad científica a quien está dirigida.
En ese contexto, la presencia de una revista científica en esos índices tiene varias consecuencias beneficiosas dignas de mención: adquiere una visibilidad universal por su acceso desde diversas latitudes, promueve el prestigio de los autores al ser considerados por sus pares y permite un mayor intercambio científico y técnico entre los investigadores.

En el caso de nuestra Revista Methodo, desde su nacimiento en 2016, fue adquiriendo visibilidad creciente, desde su primer número por su indización en CAICyT-CONICET para obtener el ISSN (International Standard Serial Number), se registró en crossref para obtener el DOI (Digital Object Identifier) y se admitió en Google Académico. En 2018, se incluyó en DIALNET, base de datos de la Universidad de La Rioja, España y Latindex Directorio. Calificó para ser incluida en Latindex Catálogo V2 en 2019. Finalmente, en el mes de agosto del corriente año, se aprobó su incorporación a DOAJ (Directory Open Access Journals), una base de datos de revistas de Tecnología, Ciencias Sociales, Humanidades y Medicina y otras Ciencias Biológicas que tienen los más altos estándares de calidad.

Para cumplir estos objetivos, fue condición indispensable avanzar cada día en la calidad de nuestra propuesta, producto del esfuerzo del Equipo Editorial, los Revisores nacionales e internacionales y de los investigadores que confiaron en nuestro proyecto editorial. 
Por siempre hemos escuchado que publicar en una revista "joven" que no genera impacto inicial por su escaso tiempo transcurrido en la consideración de pares, no es atractiva para enviar un trabajo científico. Pero también es cierto que si no se publica no se genera el progreso de la publicación $\mathrm{y}$, por ende, el intento y su impacto quedan truncos. Es por ello que los investigadores, de nuestra Universidad y de otras muy prestigiosas, son los destinatarios principales de nuestro reconocimiento por el desinteresado aporte al progreso de la revista Methodo, que hoy se ve plasmado en su indización en DOAJ.

Queda mucho camino para recorrer, pero estos hechos tan gratificantes significan para todos nosotros el compromiso de redoblar el esfuerzo día a día para lograr nuevos objetivos de indización que permitan consolidarla como una revista de Ciencias Biológicas de referencia.

Estamos seguros que con la participación de los investigadores, el apoyo de nuestros lectores y nuestro trabajo editorial lo lograremos.

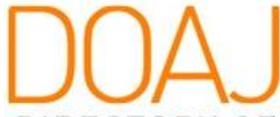

DIRECTORY OF

OPEN ACCESS

JOURNALS

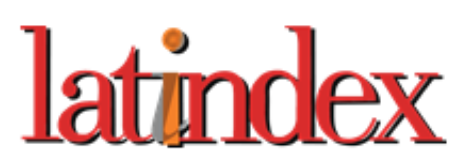

O Dialnet plus

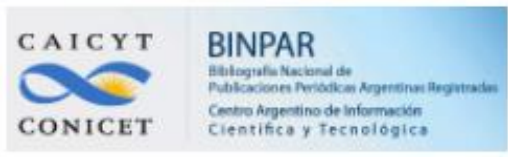

Google Académico

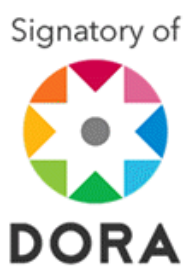

